\title{
Agmatine Protects against Zymosan-Induced Acute Lung Injury in Mice by Inhibiting NF- $\kappa$ B-Mediated Inflammatory Response
}

\author{
Xuanfei Li, Zheng Liu, He Jin, Xia Fan, Xue Yang, Wanqi Tang, \\ Jun Yan, and Huaping Liang \\ State Key Laboratory of Trauma, Burns and Combined Injury, Research Institute of Surgery, Daping Hospital, \\ The Third Military Medical University, Chongqing 400042, China
}

Correspondence should be addressed to Huaping Liang; 13638356728@163.com

Received 16 February 2014; Revised 8 July 2014; Accepted 29 July 2014; Published 27 August 2014

Academic Editor: Baoli Cheng

Copyright (C) 2014 Xuanfei Li et al. This is an open access article distributed under the Creative Commons Attribution License, which permits unrestricted use, distribution, and reproduction in any medium, provided the original work is properly cited.

Acute lung injury (ALI) is characterized by overwhelming lung inflammation and anti-inflammation treatment is proposed to be a therapeutic strategy for ALI. Agmatine, a cationic polyamine formed by decarboxylation of L-arginine, is an endogenous neuromodulator that plays protective roles in diverse central nervous system (CNS) disorders. Consistent with its neuromodulatory and neuroprotective properties, agmatine has been reported to have beneficial effects on depression, anxiety, hypoxic ischemia, Parkinson's disease, and gastric disorder. In this study, we tested the effect of agmatine on the lung inflammation induced by Zymosan (ZYM) challenge in mice. We found that agmatine treatment relieved ZYM-induced acute lung injury, as evidenced by the reduced histological scores, wet/dry weight ratio, and myeloperoxidase activity in the lung tissue. This was accompanied by reduced levels of TNF- $\alpha$, IL-1 $\beta$, and IL-6 in lung and bronchoalveolar lavage fluid and decreased iNOS expression in lung. Furthermore, agmatine inhibited the phosphorylation and degradation of $\mathrm{I} \kappa \mathrm{B}$ and subsequently blocked the activation of nuclear factor (NF)- $\kappa \mathrm{B}$ induced by Zymosan. Taken together, our results showed that agmatine treatment inhibited NF- $\kappa$ B signaling in lungs and protected mice against ALI induced by Zymosan, suggesting agmatine may be a potential safe and effective approach for the treatment of ALI.

\section{Introduction}

Acute lung injury (ALI) and acute respiratory distress syndrome (ARDS), which is the severest form of injury, are the leading causes of morbidity and mortality in critically ill patients [1]. ALI is characterized by the development of hypoxemia, damage to the alveolar capillary membrane barrier, pulmonary edema, and the resultant respiratory failure [2]. Current therapeutic strategy includes protective ventilation and supportive fluid conservative [3]. Although extensive studies about the pathogenesis of ALI have been conducted, the mortality of ALI remains very high [4]. Thus, it is critical to explore the innovative therapies and effective medications for ALI.

Among the animal models established for the investigation of mechanism involved in ALI, intraperitoneal injection of Zymosan (ZYM) is one of the most commonly used models of ALI [5]. Zymosan is a substance derived from the cell wall of the yeast Saccharomyces cerevisiae. When injected into animals, ZYM induces inflammation by a series of mechanisms. Reports show that the onset of ZYMinduced inflammatory response in mouse lung is associated with the gas exchange barrier and that it culminates with maximal neutrophil accumulation, exudate formation, and proinflammatory cytokines production $[6,7]$. ZYM is recognized by toll-like receptor 2 (TLR-2) on immune cells (e.g., neutrophils), which subsequently trigger signal cascade for nuclear factor- $\kappa \mathrm{B}(\mathrm{NF}-\kappa \mathrm{B})$ activation [8]. NF- $\kappa \mathrm{B}$ activation is required for maximal expression of many proinflammatory cytokines and chemokines and iNOS involved in the pathogenesis of acute lung injury [9].

Agmatine, a biogenic amine formed by arginine decarboxylation, is widely but unevenly distributed in mammalian tissues. Agmatine has been reported to have various biological actions. It attenuates morphine withdrawal syndromes, inhibits inducible nitric oxide synthase (NOS), and 
contributes to polyamine homeostasis [10]. Additionally it is known to exert antidepressant, anxiolytic, antitumor cell proliferative and anticonvulsive effects [11]. However, the precise working mechanisms of agmatine are not yet fully understood. The aim of our study was to investigate the protective effects of agmatine on Zymosan-induced acute lung injury and to assess its relative mechanisms.

\section{Materials and Methods}

2.1. Reagents. Zymosan and agmatine were obtained from Sigma-Aldrich. Antibodies against iNOS, NF- $\kappa$ B p $65, \mathrm{I} \kappa \mathrm{B}-\alpha$, and $\beta$-actin were obtained from Santa Cruz Biotechnology (Santa Cruz, CA), and those against phosphor (p)-I $\kappa \mathrm{B}$ and NF- $\kappa$ B p 65 were from Cell Signaling Tech (Danvers, MA). Mouse TNF- $\alpha$, IL- $1 \beta$, and IL- 6 enzyme-lined immunosorbent assay (ELISA) kits were purchased from Boster Biotechnology (Wuhan, China). All suspensions were freshly made before use.

2.2. Animals and Treatments. Male C57Bcl/6 mice (weighing $18-22 \mathrm{~g}$ ) were used in this study. Animal procedures were approved by the Ethics Committee for Animal Experimentation of Third Military Medical University. An inflammationassociated lung injury model was established by aseptic intraperitoneally (IP) injection of ZYM $(30 \mathrm{mg} / \mathrm{mL}$ suspended in normal Saline (NS)) into mice, at a dose of $600 \mathrm{mg} / \mathrm{kg}$ of body weight, as previously described [12]. The same volume of NS was injected through the same route as the sham control.

2.3. Histologic Examination. Lungs were harvested for observing morphologic alterations at 24 hrs after ZYM or NS administration. The subjects were fixed with $10 \%$ formalin for $8 \mathrm{hrs}$ at room temperature, embedded in paraffin, and sectioned at $5 \mu \mathrm{m}$ thickness. After deparaffinization and rehydration, the sections were sequentially stained with hematoxylin and eosin. Histologic changes were evaluated by two independent pathologists, who had no knowledge of the treatment regimen received by each respective animal. The degree of lung injury was scored on a subjective scale ranging from 0 to $3 ; 0=$ absence, $1=$ mild, $2=$ moderate, and $3=$ severe. The ranging scale was used for each of histologic features: congestion, edema, inflammation, and hemorrhage. The final score will be the adding of the single evaluation.

2.4. Wet/Dry Weight Ratio. To quantify the magnitude of pulmonary edema, we evaluated lung wet/dry (W/D) weight ratio at $24 \mathrm{hrs}$ after NS or ZYM administration. The harvested wet lung was weighed and then placed in an oven for $24 \mathrm{hrs}$ at $80^{\circ} \mathrm{C}$ and weighed when it was dried. The ratio of wet lung to dry lung was calculated [13].

2.5. BALF Collection. At $24 \mathrm{hrs}$ after administration of ZYM or NS, BALF collection was performed by the methods described previously [14]. The mice were anesthetized with pentobarbital, tracheas were cannulated after exsanguination, and lungs were gently washed with $2 \mathrm{~mL}$ of PBS. The amount of exudate was calculated by subtracting the volume injected $(2 \mathrm{~mL})$ from the total volume recovered. BALF samples were centrifuged at $500 \mathrm{~g}$ at $4^{\circ} \mathrm{C}$ for $12 \mathrm{mins}$, and the supernatant was stored at $-70^{\circ} \mathrm{C}$ for subsequent analysis of protein and cytokine levels.

2.6. Measurement of Lung MPO Activity. Myeloperoxidase (MPO) activity was measured as an indicator of neutrophil infiltration into the lung tissue as previously described [15]. At 24 hrs after ZYM or NS injection, all animals $(n=8$ for each group) were sacrificed with pentobarbital. Lungs were obtained and perfused with cold PBS to remove all blood, and homogenated lung supernatants were prepared to detect the activity of MPO. MPO activity was defined by the change in absorbance measured by spectrophotometer at $590 \mathrm{~nm}$ and expressed in unit per gram weight of wet tissue. The activity of MPO was measured by using commercial kits purchased from Boster Biotechnology (Wuhan, China).

2.7. Measurement of Cytokine Production. At 6 hrs after ZYM or NS injection, the cytokines levels in BALF and lung tissue were measured using commercially available enzyme-linked immunosorbent assay (ELISA) kits (mouse TNF- $\alpha$, IL- $1 \beta$, and IL-6 ELISA kits are from Boster Biotechnology, Wuhan, China). The optical density (OD) was measured on an ELISA plate scanner. All experiments were performed according to the manufacturers' instructions.

2.8. Immunohistochemistry. Immunohistochemistry was performed as previously described [16]. At $24 \mathrm{hrs}$ after ZY or NS injection, the lung tissues were fixed in 10\% PBS-buffered formalin, and $5 \mu \mathrm{m}$ sections were prepared from paraffinembedded tissues. After deparaffinization, endogenous peroxidase was blocked with $0.3 \%$ (volume/volume [v/v]) hydrogen peroxide in $60 \%(\mathrm{v} / \mathrm{v})$ methanol for 30 mins. The sections were permeabilized with $0.1 \%$ (v/v) PBS-buffered Triton X-100 for 20 mins. Incubate the section in 3\% (v/v) normal goat serum in PBS for 20 mins to minimize the nonspecific adsorption. Endogenous biotin or avidin binding sites were blocked by sequential incubation for 15 mins with avidin and biotin (BD Biosciences, CA, USA). The sections were then incubated overnight with rabbit anti-iNOS $\mathrm{mAb}$ (Santa Cruz, CA, USA, 1:500 in PBS, v/v) or with control solutions. A biotin-conjugated specific secondary antiimmunoglobulin $\mathrm{G}$ and avidin-biotin peroxidase complex were used to detect the specific labeling. To verify the binding specificity for iNOS, some sections were also incubated with primary antibody only (no secondary antibody) or with secondary antibody only (no primary antibody). In these situations, no positive staining was found in the sections indicating that the immunoreactions were positive in all the experiments carried out.

2.9. Western Blot Analysis. The lung tissues were harvested, after mice were killed, and homogenized immediately. Cytoplasmic proteins were extracted from the lungs using Cytoplasmic Protein Extraction Kit (Beyotime Biotechnology, Jiangsu, China) according to the manufacturer's protocol. 
For extraction of nucleoprotein, lung tissue were homogenized and lysed in the lysis buffer $(10 \mathrm{mM}$ Hepes $\mathrm{pH} 7.9$, $1.5 \mathrm{mM} \mathrm{MgCl}_{2}, 10 \mathrm{mM} \mathrm{KCl}, 0.5 \mathrm{mM}$ DTT, 2\% NP-40, and $1 \mathrm{mM}$ PMSF) for $30 \mathrm{~min}$. After that, the lysis buffer was centrifugated at $1,2000 \times \mathrm{g}$ for 15 minutes. Then the supernatant was collected as cytoplasmic protein. Precipitation was washed twice and lysed in the lysis buffer containing Triton X-100 as nucleoprotein. Protein concentrations were determined by BCA protein assay kit. The protein samples were separated by $10 \%$ sodium dodecyl sulfatepolyacrylamide gel electrophoresis and were transferred to a polyvinylidene difluoride membrane. The membrane was incubated overnight with antibodies against iNOS $(1: 400)$, $\mathrm{I} \kappa \mathrm{B}-\alpha(1: 800), \mathrm{p}-\mathrm{I} \kappa \mathrm{B}-\alpha(1: 1000), \beta$-actin $(1: 1000), \mathrm{NF}-\kappa \mathrm{B}$ p65 (1:800), and LaminB1 $(1: 1000)$. The membrane was then incubated with the secondary antibodies (anti-rabbit or antimouse IgG peroxidase conjugated, 1:10000). The blots were visualized with ECL-Plus reagent (Sigma).

2.10. NF- $\kappa B$ DNA Binding Activity Assay. At $6 \mathrm{hrs}$ after ZY or NS injection, nuclear extracts of homogenated lung tissue were prepared. The DNA binding activity of $\mathrm{NF}-\kappa \mathrm{B}$ in lung tissues was quantified using the TransAM NF- $\kappa$ B p65 transcription factor assay kit (Active Motif, Carlsbad, CA). According to the manufacturer's instructions, all standards and samples were run in duplicate.

2.11. Statistical Analysis. Data were expressed as mean \pm SEM. Differences between groups were examined for statistical significance using one-way analysis of variance with Student's $t$-test. A $P$ value less than 0.05 was considered statistically significant.

\section{Results}

3.1. Agmatine Relieves Zymosan-Induced Lung Injury in Mice. Lung injury was characterized by alveolar thickening, infiltration of neutrophils into the lung interstitium, and alveolar space as well as alveolar hemorrhage. As shown in Figure 1(a), the mice in the control group or AGM-treated alone group showed no significant morphologic damages, indicating that intraperitoneal administration with Saline did not induce additional inflammation response in this protocol. However, ZYM-challenged mice appeared to have significant neutrophil infiltration into lung interstitium, alveolar wall thickening, and alveolar hemorrhage. Interestingly, agmatine treatment reduced infiltrated inflammatory cells and improved lung architecture in ZY-challenged mice. A scoring system was used to grade the degree of lung injury by evaluating congestion, edema, inflammation, and hemorrhage. Lung histologic scores significantly increased in ZYchallenged mice $(P<0.05)$ but were reduced by agmatine treatment $(P<0.05)$ (Figure $1(\mathrm{~b}))$.

3.2. Agmatine Downregulates Zymosan-Induced TNF- $\alpha$, IL$1 \beta$, and IL-6 in Lung and BALF. To test whether agmatine modulates the inflammatory process through the regulation of secretion of proinflammatory cytokines, we detected the levels of TNF- $\alpha$, IL- $1 \beta$, and IL- 6 in lung and BALF. Six hours after ZYM or Saline injection, the lung and BALF were obtained and measured by ELISA analysis. In the Zymosan group, the concentration of TNF- $\alpha$, IL- $1 \beta$, and IL- 6 in lung $(1521.5 \pm 128.4,718.5 \pm 67.2$, and $917.4 \pm 89.5$, resp. $)$ and $\operatorname{BALF}(157.5 \pm 13.4,124.7 \pm 23.9$, and $197.1 \pm 24.3$, resp.) increased significantly compared with that of the sham group in lung $(421.1 \pm 38.4,114.8 \pm 16.4$, and $135.2 \pm 17.4$, resp.) and in BALF $(8.1 \pm 1.2,6.5 \pm 2.1$, and $13.5 \pm 4.2$, resp.) (all $P<0.05)$. However, in the ZYM + AGM group, the levels of TNF- $\alpha$, IL-1 $\beta$, and IL-6 in lung (926.2 \pm 89.4, $495.5 \pm 54.2$, and $424.3 \pm 74.7$, resp. $)$ and $\operatorname{BALF}(56.7 \pm 17.5,35.02 \pm 4.7$, and $70.5 \pm 33.6$, resp.) were significantly lower compared with that of the Zymosan group (all $P<0.05$ ) (Figure 2).

\subsection{Effects of Agmatine on Zymosan-Induced Wet/Dry Weight} Ratio, Protein in BALF, and MPO Activity. The pathogenesis of ALI involves increased permeability of the alveolarcapillary membrane, accumulation of protein-rich fluid in the airspaces, pulmonary edema, and pulmonary infiltration of neutrophils. In our study, twenty-four hour after Zymosan challenge, the lung tissues were obtained to employ lung weight and dry ratio (W/D), protein concentration in BALF, and MPO activity. In the Zymosan group, the $W / D$ ratio $(6.2 \pm 0.6)$ was significantly increased compared with that of the Saline group $(2.9 \pm 0.4 ; P<0.05)$. However, the ratio was significantly decreased in the ZYM + AGM group $(4.1 \pm 0.5 ; P<0.05)$ compared with that of the Zymosan group (Figure $3(\mathrm{a})$ ). Besides, the protein concentration in bronchoalveolar lavage fluid (BALF) was also increased in Zymosan group $(0.71 \pm 0.22)$ compared with that of the Saline group $(0.06 \pm 0.01 ; P<0.05)$, whereas its level in $\mathrm{ZYM}+$ AGM group $(0.29 \pm 0.11)$ was significantly lower than that of the Zymosan group $(P<0.05)$ (Figure $3(\mathrm{~b}))$. MPO activity, a biochemical marker of neutrophil infiltration, rose to $25.2 \pm$ 1.8 in the lung of the Zymosan group compared with that of the Saline group $(5.2 \pm 1.4 ; P<0.05)$. Treatment with agmatine resulted in a significant reduction in the lung MPO activity of the ZYM + AGM group $(11.0 \pm 3.4 ; P<0.05)$ compared with that of the Zymosan group (Figure 3(c)).

3.4. Agmatine Reduces iNOS Expression in Lung. To understand the iNOS expression in lung, the lung tissues obtained at $24 \mathrm{~h}$ after Zymosan administration were detected by immunohistochemistry (Figure 4(a)) and Western blot analysis (Figure 4(b)). A significant increase of iNOS expression in ZYM group was detected compared to that in Saline group by evaluating gray level ratio of iNOS/ $\beta$-actin $(0.78 \pm$ 0.12 versus $0.05 \pm 0.03, P<0.05)$. However, agmatine treatment significantly attenuated iNOS expression in the lung compared to that in Saline group $(0.23 \pm 0.12$ versus $0.78 \pm 0.12, P<0.05)$.

3.5. Agmatine Inhibits Zymosan-Induced NF- $\kappa B$ Activation and DNA Binding Activity in Lung. Nuclear factor (NF) $\kappa \mathrm{B}$ signaling plays a central role in the initiation and regulation of cellular inflammatory response to bacterial stimuli. Thus, to investigate the mechanisms in which agmatine enhanced 


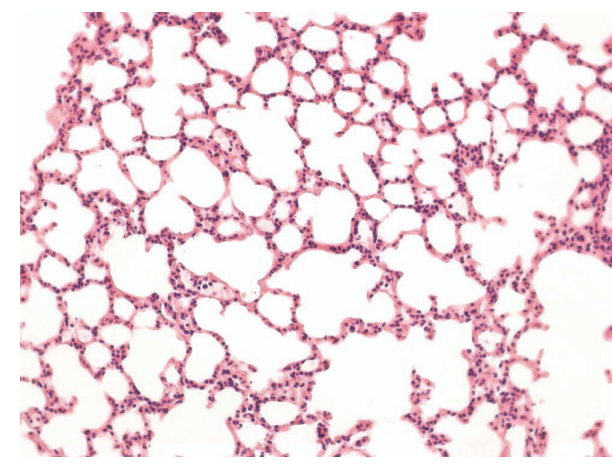

(A)

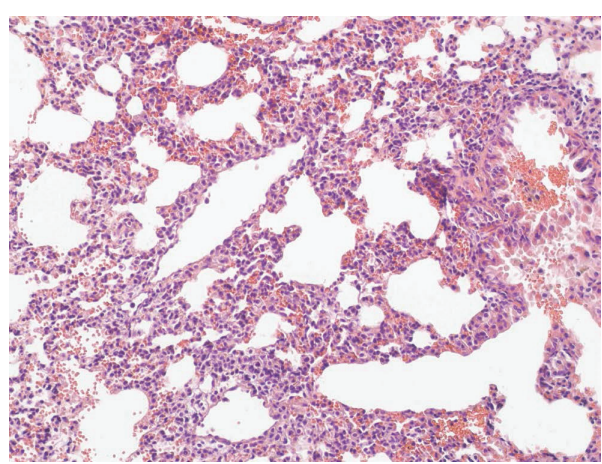

(C)

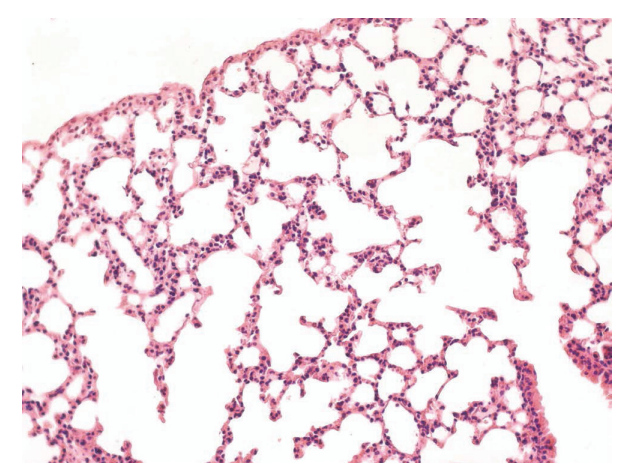

(B)

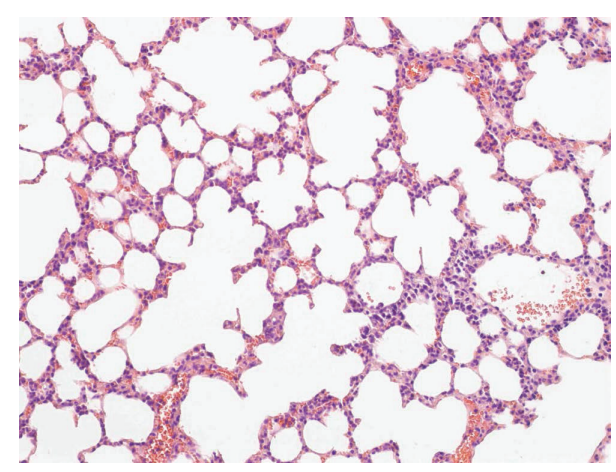

(D)

(a)

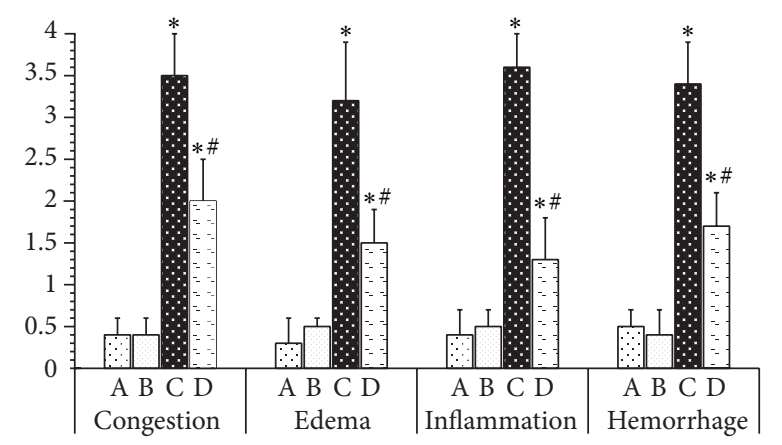

(b)

FIGURE 1: Agmatine relieves Zymosan-induced lung injury in mice. (a) Representative micrographs of H\&E staining. Lung tissues in NS group (A), agmatine group (B), Zymosan group (C), and Zymosan + agmatine group (D) were measured. (b) The degree of lung injury was scored by evaluating each of histologic features: congestion, edema, inflammation, and hemorrhage. ${ }^{*} P<0.05$ compared with NS group. ${ }^{\#} P<0.05$ compared with Zymosan group.

lung inflammation resolution, we assessed the effects of agmatine on the degradation of $\mathrm{I} \kappa \mathrm{B}-\alpha$ and activation of NF$\kappa \mathrm{B}$ by Western blot analysis, and further we detected its effect on DNA binding activity. The mice treated with ZYM exhibited significant degradation of $\mathrm{I} \kappa \mathrm{B}-\alpha$ in lungs, whereas agmatine treatment at the dose of $200 \mathrm{mg} / \mathrm{kg}$ prevented the I $\kappa \mathrm{B}-\alpha$ degradation. In contrast, ZYM challenge induced the nuclear translocation of NF- $\kappa \mathrm{B}$ p65 subunit, compared with basal group. Agmatine treatment inhibited the nuclear translocation of NF- $\kappa$ B p65 (Figure 5(a)). Furthermore, the Zymosan administration significantly increased NF- $\kappa$ B p 65
DNA binding activity in ZYM group compared with that in Saline group $(2.70 \pm 0.25$ versus $1.10 \pm 0.12, P<0.05)$, whereas its activity in ZYM + AGM group was inhibited compared with that in ZYM group $(1.82 \pm 0.21$ versus $2.70 \pm$ $0.25, P<0.05$ ) (Figure 5(b)).

\section{Conclusion}

Zymosan has been well recognized in the pathogenesis of ALI. Experimental administration of Zymosan, both systemically and intratracheally, has been used to induce neutrophil 


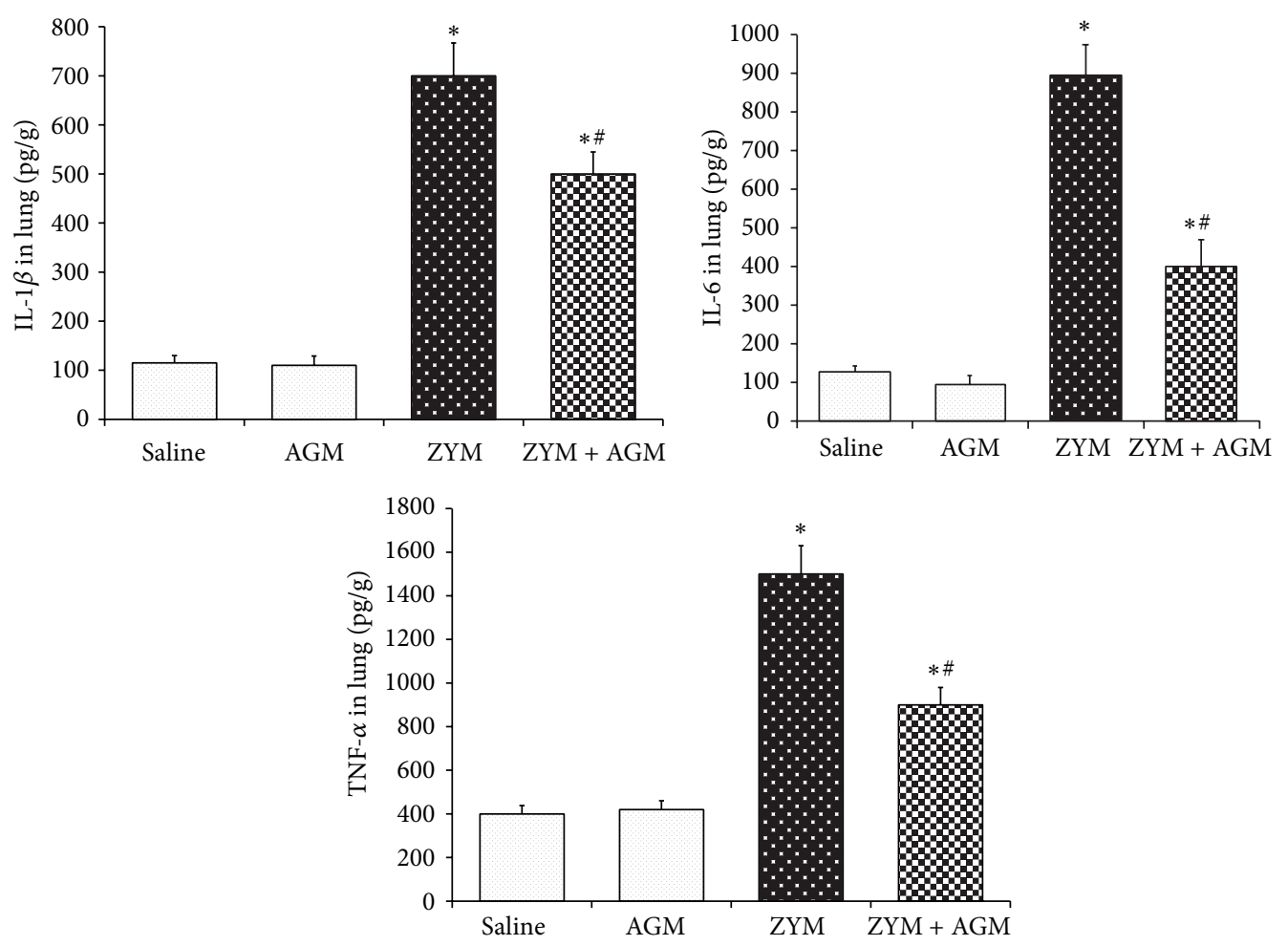

(a)
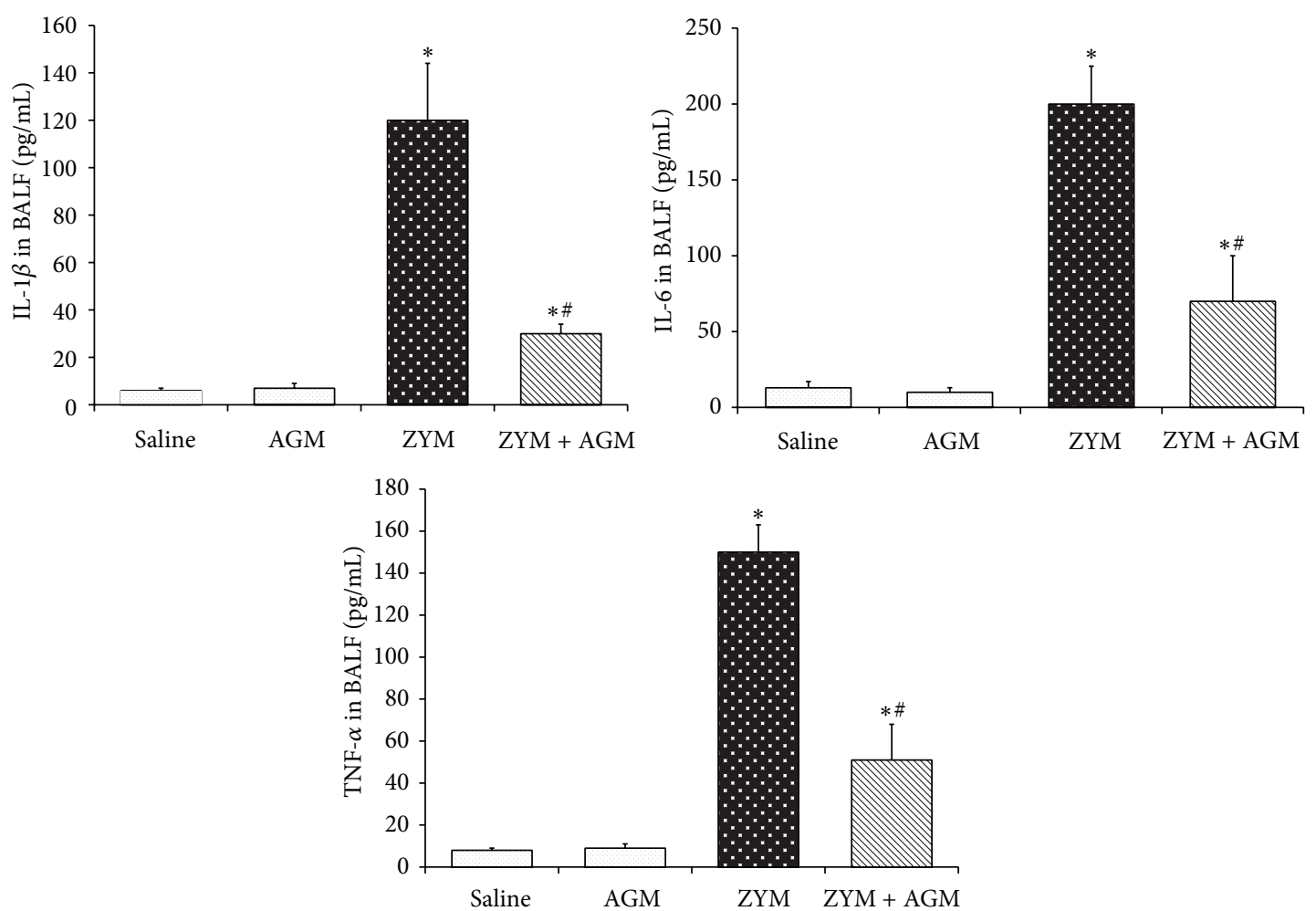

(b)

FIgURE 2: Agmatine downregulates Zymosan-induced TNF- $\alpha$, IL-1 $\beta$, and IL- 6 in lung and BALF. At 6 hr after ZYM or Saline injection, the cytokines levels in lung and BALF tissue were measured using commercially available enzyme-linked immunosorbent assay (ELISA) kits. ${ }^{*} P<0.05$ compared with NS group. ${ }^{\#} P<0.05$ compared with Zymosan group. 


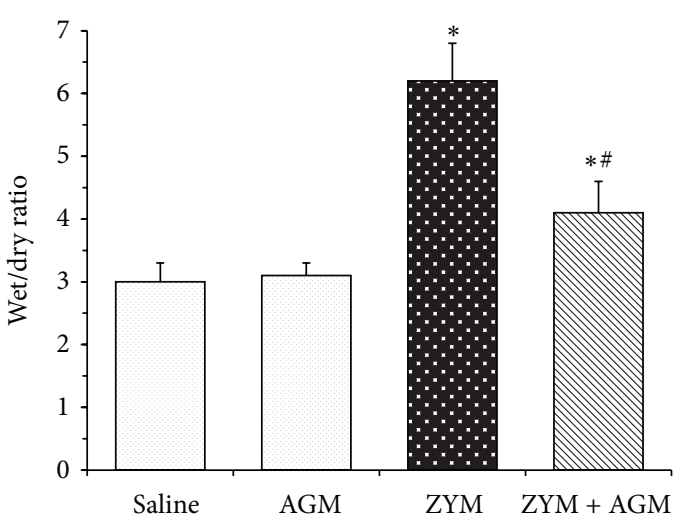

(a)

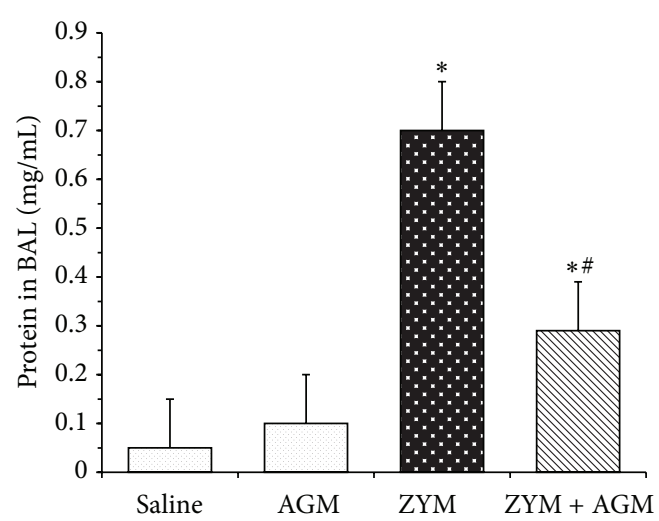

(b)

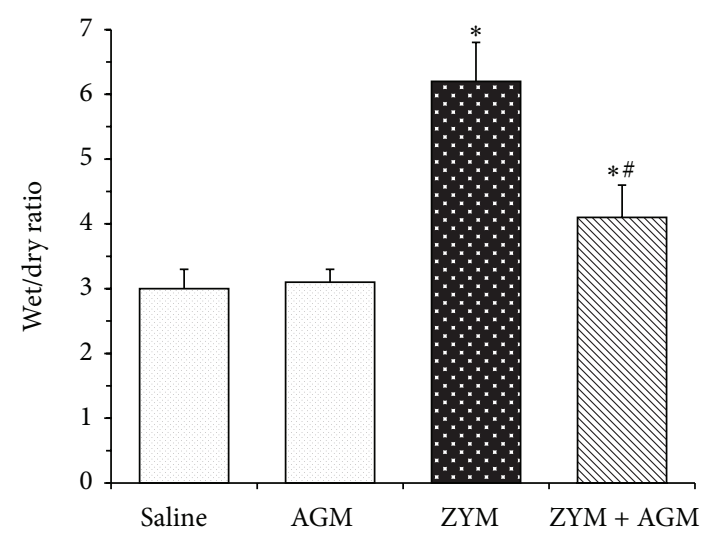

(c)

FIGURE 3: Effects of agmatine on Zymosan-induced wet/dry weight ratio, protein in BALF, and MPO activity. 24 hour after Zymosan challenge, the lung tissues were obtained to detect lung weight and dry ratio (W/D) (a), protein concentration in BALF (b), and MPO activity (c). ${ }^{*} P<0.05$ compared with NS group. ${ }^{\#} P<0.05$ compared with Zymosan group.

infiltration and develop pulmonary inflammation in animal models $[17,18]$. In the present study, we demonstrated that agmatine protected against ZYM-induced lung inflammation and lung injury in mice. Agmatine treatment inhibited the neutrophil infiltration and lung endothelial permeability in lung of ZYM-challenged mice. Histopathological examination showed that ZYM-induced congestion, edema, inflammation, and hemorrhage in lung were relieved by agmatine. In addition, ZYM induced upregulations of proinflammatory mediators and cytokines in BALF and lung were partially inhibited by agmatine. Furthermore, agmatine treatment inhibited the degradation of $\mathrm{I} \kappa \mathrm{B}-\alpha$ and subsequent activation and DNA binding activity of NF- $\kappa \mathrm{B}$ in lung. These results demonstrate that agmatine exerts a protective effect on ALI via inhibiting NF- $\kappa \mathrm{B}$-mediated inflammatory response.

ALI is characterized by excessive neutrophil infiltration, release of proinflammatory mediators, and loss of vascular barrier integrity [19]. During airway inflammation, neutrophils are the first cells to be recruited and are the predominant cause of tissue damage [20]. Activated neutrophils induce extensive lung inflammation and the destruction of basement membrane and increase the permeability of alveolar capillary membrane [21]. Besides, neutrophils can release damaging mediators, such as cytokines and oxidants, leading to the injury of epithelial-vascular barrier [22]. In the present study, Zymosan-induced mice group caused excessive production of MPO, an enzyme located mainly in the primary granules of neutrophils. Agmatine treatment significantly reduced neutrophil infiltration by determining MPO activity in lung. Furthermore, we detected less protein concentration in BAL and lung W/D weight in mice treated with agmatine, showing the protective effect of agmatine against lung endothelial permeability injury.

Except for neutrophils and the other inflammatory cells, the release of proinflammatory mediators has been reported to be involved in inflammatory cascade [23]. Among them, TNF- $\alpha$, IL- $1 \beta$, and IL- 6 were considered the most important inflammatory mediators in innate immune response. It has been reported that resident alveolar macrophages release TNF- $\alpha$ and IL- $1 \beta$ in early phase of ALI in response to ZYM stimulation, resulting in the subsequent inflammatory cascade and tissue injury [24]. It is reported that TNF- $\alpha$ elevates intracellular reactive oxygen species which causes mitochondrial damage or ion exchange dysfunction across 


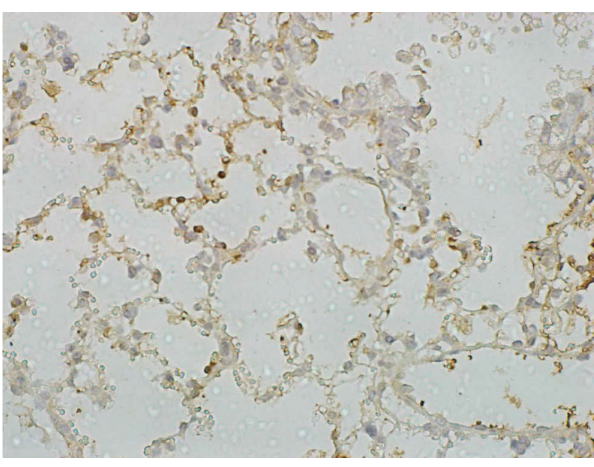

(A)

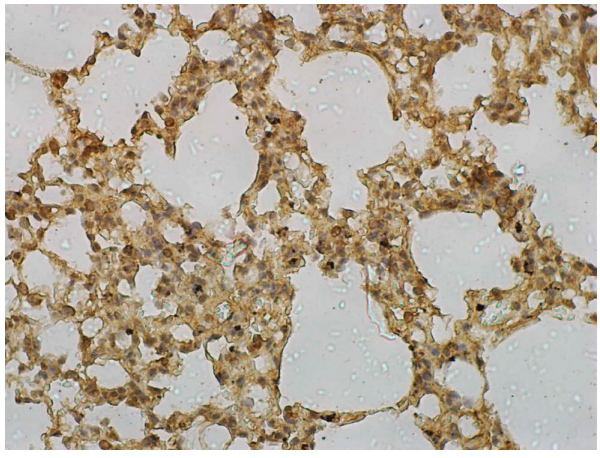

(C)

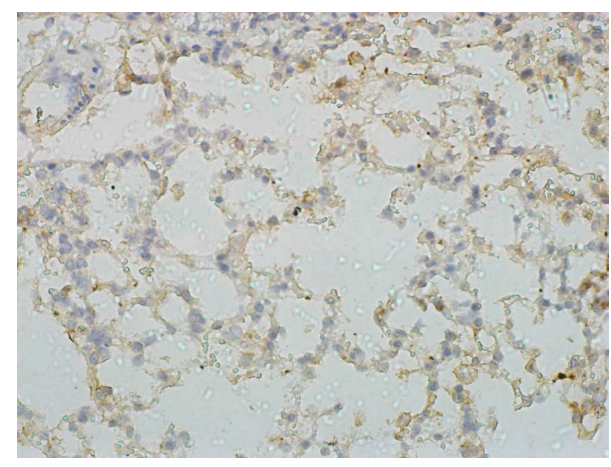

(B)

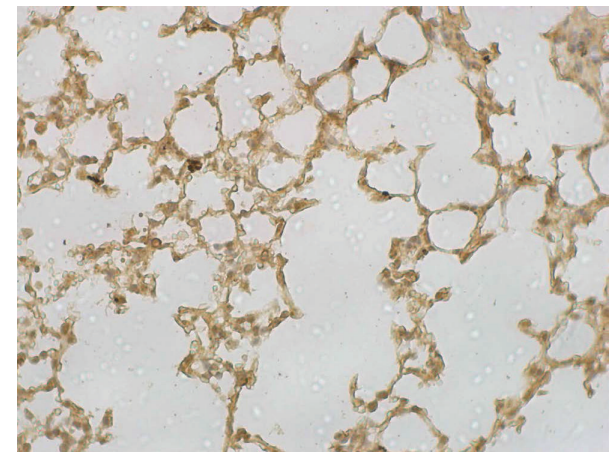

(D)

(a)
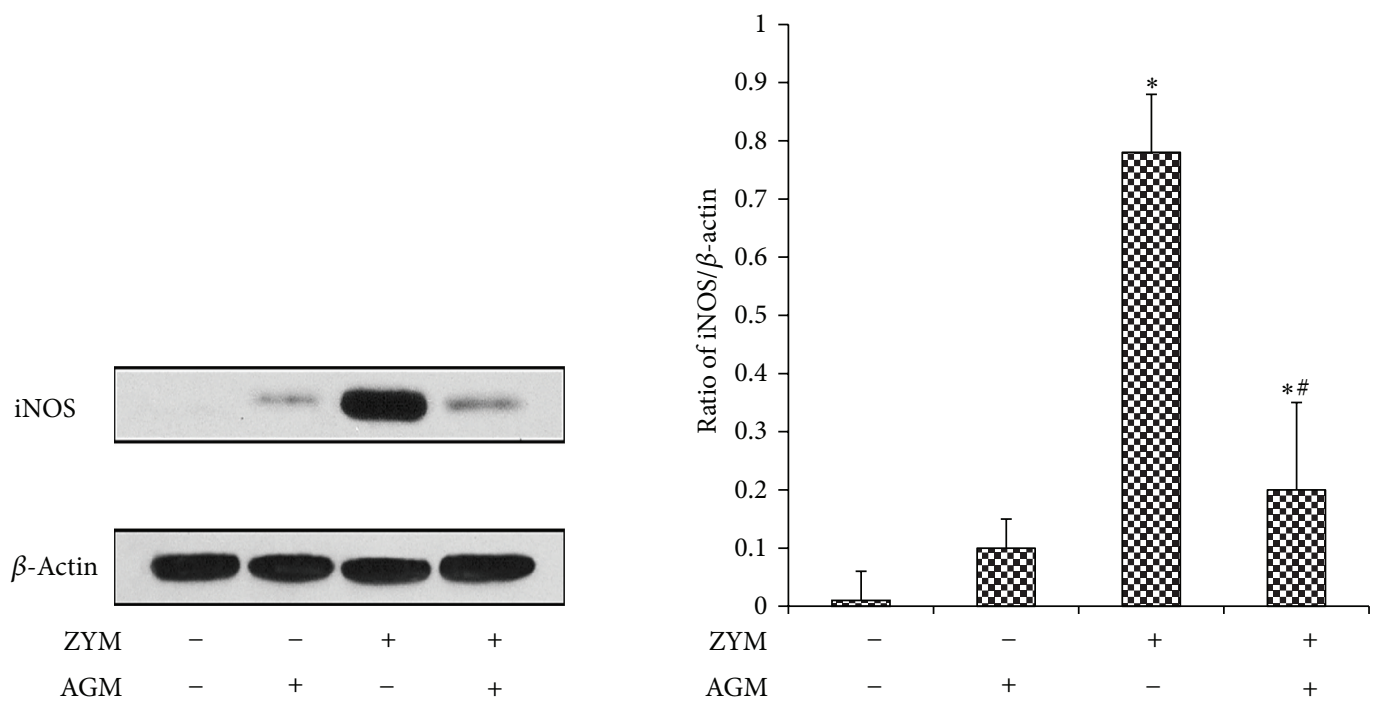

(b)

FIgURE 4: Agmatine decreases iNOS expression in lung. (a) Lung samples were obtained from NS group (A), agmatine group (B), Zymosan group (C), and Zymosan + agmatine group (D) for immunohistochemical staining. (b) Lungs were harvested for observing iNOS expression at $24 \mathrm{hrs}$ after ZYM or NS administration by Western blot. ${ }^{*} P<0.05$ compared with NS group. ${ }^{*} P<0.05$ compared with Zymosan group.

the cell membrane $[25,26]$. Besides, inhibition of TNF- $\alpha$ was proved to be protective in an animal model of ALI [27]. IL$1 \beta$ also enhances the recruitment of inflammatory cells into airspaces and alters vascular permeability leading to fluid transport and subsequent lung edema formation [28]. During inflammation, elevated TNF- $\alpha$ and IL- $1 \beta$ are associated with a poor ALI prognosis [29]. In the present study, the expressions of TNF- $\alpha$, IL- $1 \beta$, and IL- 6 in lung and BALF were markedly induced by ZYM challenge, which was blocked by the treatment of agmatine. Our results confirmed the link 


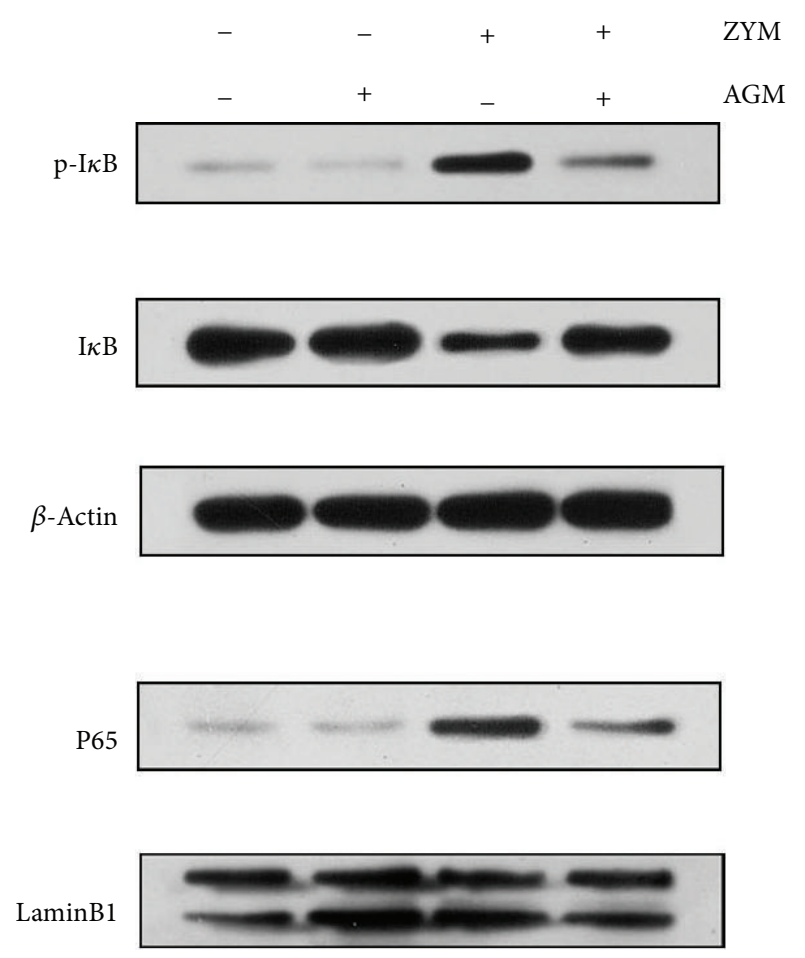

(a)

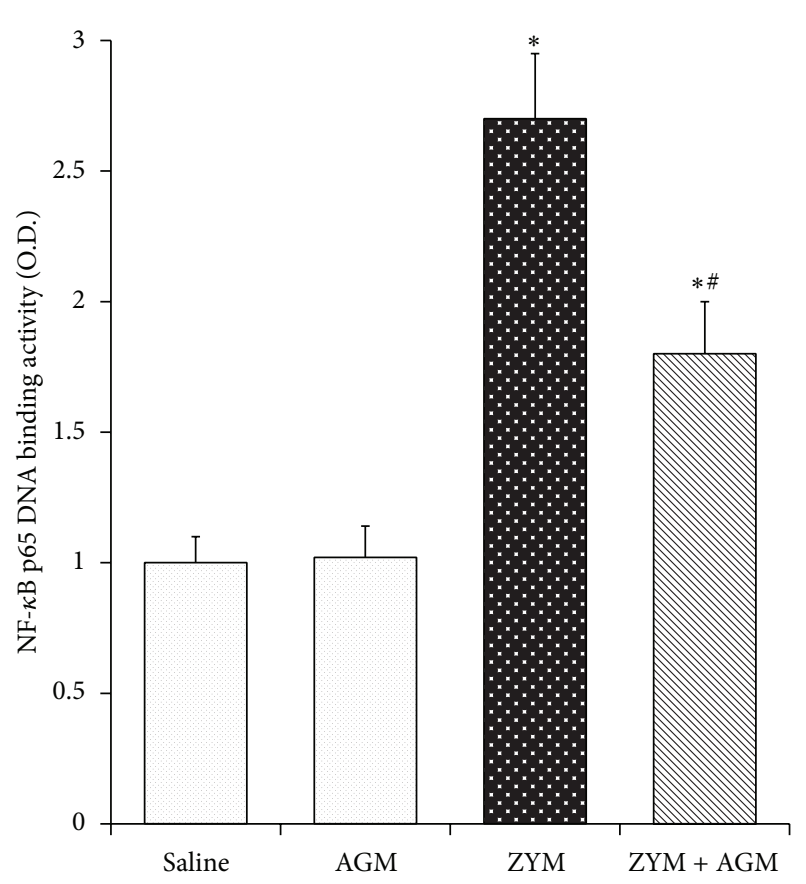

(b)

FIGURE 5: Agmatine inhibits Zymosan-induced NF- $\kappa$ B activation and DNA binding activity in lung. $6 \mathrm{~h}$ after ZYM injection with or without agmatine treatments, mice were exsanguinated and their lungs were removed. (a) Western blot was performed to detect p-I $\kappa \mathrm{B}-\alpha$ and $\mathrm{I} \kappa \mathrm{B}-\alpha$ in cytoplasm and NF- $\kappa$ B p 65 in nucleus. Expressions of $\beta$-actin and LaminB1 were shown as loading controls. (b) DNA binding activity of NF- $\kappa$ B p 65 was examined by a TransAM p 65 transcription factor ELISA kit. Each bar represents the mean \pm SD of 8 mice. ${ }^{*} P<0.05$ compared with NS group. ${ }^{\#} P<0.05$ compared with Zymosan group.

between the inflammatory cytokine levels and the extent of lung inflammation, demonstrating the anti-inflammatory effects of agmatine.

Inflammatory activity is mediated by the endogenous free radical NO, which is produced at high levels upon the induction of NO synthase by inflammatory stimulus [30]. In an experimental murine model, ZY administration increases iNOS expression and activity that exacerbates nonseptic shock and leads to cellular and tissue damage including lung injury if unchecked. However, iNOS inhibitors suppress airway inflammation in mice by downregulating proinflammation and chemokine expression that are detrimental to the lung [31]. iNOS-deficient mice also undergo less lung injury after ZY challenge [32]. In the present study, we demonstrated that agmatine treatment significantly reduced iNOS expression and its activity in the lung tissue, and this phenomenon significantly inhibited the inflammatory response. Moreover, NF- $\kappa \mathrm{B}$ is a potent regulator of iNOS expression [33], and our results show that agmatine treatment inhibited NF- $\kappa$ B activity as well as iNOS expression in lung. Based on these findings, we speculated that agmatine probably inhibited iNOS expression and activity by blocking NF- $\kappa$ B activation.

It has been reported that NF- $\kappa \mathrm{B}$, a transcription factor, plays a pivotal role in the pathogenesis of immune and inflammatory responses [34]. In experimental animal models of ALI, NF- $\kappa$ B activation is increased [35]. Pharmacological inhibition of NF- $\kappa$ B pathway decreases the production of proinflammatory mediators and protects against endotoxininduced ALI in animals [36]. Therefore, NF- $\kappa$ B pathway is involved in the pathogenesis of ALI and is known as an important target for anti-inflammatory molecules [37]. Our present study displayed that ZYM obviously enhanced the phosphorylation and degradation of I $\kappa \mathrm{B}-\alpha$. However, agmatine treatment dramatically regulated that this trend, which suggested that suppression of I $\kappa \mathrm{B}-\alpha$ activity may be the main reason of agmatine lessening ZYM-initiated pulmonary inflammation in mice. These results suggested that inhibition of NF- $\kappa \mathrm{B}$ signaling plays a role in the protective effects of agmatine on ALI.

Agmatine is a cationic polyamine under physiological conditions and thus is thought not to be able to permeate biological membranes, although agmatine can cross the bloodbrain barrier when administered peripherally in high doses. In mammalian tissues, agmatine binds to several receptors, including imidazoline, $\alpha 2$-adrenergic, and NMDA glutamate receptor. Sameer et al. reported that agmatine attenuated the acquisition of ethanol conditioned place preference by imidazoline $\left(\mathrm{I}_{1}\right.$ or $\left.\mathrm{I}_{2}\right)$ receptors [38]. Bhalla et al. found that agmatine potentiated oxycodone antinociception in 
mice via an imidazoline $I_{2}$ receptor-mediated mechanism [39]. Besides, agmatine was found to be protective against glutamate-induced necrotic neuronal cell death through NMDA receptor blockade by interacting with a site located within the NMDA channel pore [40]. Therefore, we speculated that agmatine may protect against zymosan-induced acute lung injury by interacting with its endogenous receptors, which will be tested and verified in the next round of experiments.

In summary, we have demonstrated the protective effects of agmatine on ZYM-induced ALI. It is evidenced by alleviating lung inflammation, reducing neutrophil infiltration, decreasing vascular leakage, and proinflammatory cytokine release, inhibiting NF- $\kappa \mathrm{B}$ activation and DNA binding activity in ZYM-challenged mice. These results suggest agmatine may be considered as an effective and safe drug for the potential treatment of ALI.

\section{Conflict of Interests}

The authors declare that no conflict of interests exists.

\section{Acknowledgments}

This work was supported by a Grant from National “973” Project (no. 2012CB518102).

\section{References}

[1] J. Aman, M. van der Heijden, A. van Lingen et al., "Plasma protein levels are markers of pulmonary vascular permeability and degree of lung injury in critically ill patients with or at risk for acute lung injury/acute respiratory distress syndrome," Critical Care Medicine, vol. 39, no. 1, pp. 89-97, 2011.

[2] M. A. Matthay, G. A. Zimmerman, C. Esmon et al., "Future research directions in acute lung injury: summary of a National Heart, Lung, and Blood Institute Working Group," The American Journal of Respiratory and Critical Care Medicine, vol. 167, no. 7, pp. 1027-1035, 2003.

[3] G. Matute-Bello, G. Downey, B. B. Moore et al., "An official american thoracic society workshop report: features and measurements of experimental acute lung injury in animals," American Journal of Respiratory Cell and Molecular Biology, vol. 44, no. 5, pp. 725-738, 2011.

[4] G. D. Rubenfeld, E. Caldwell, E. Peabody et al., "Incidence and outcomes of acute lung injury," New England Journal of Medicine, vol. 353, no. 16, pp. 1685-1693, 2005.

[5] C. Metz and W. J. Sibbald, "Anti-inflammatory therapy for acute lung injury: a review of animal and clinical studies," Chest, vol. 100, no. 4, pp. 1110-1119, 1991.

[6] M. P. Young, H. L. Manning, D. L. Wilson et al., "Ventilation of patients with acute lung injury and acute respiratory distress syndrome: has new evidence changed clinical practice?" Critical Care Medicine, vol. 32, no. 6, pp. 1260-1265, 2004.

[7] H. V. Chaves, R. D. A. Ribeiro, A. M. B. de Souza et al., "Experimental model of zymosan-induced arthritis in the rat temporomandibular joint: role of nitric oxide and neutrophils," Journal of Biomedicine and Biotechnology, vol. 2011, Article ID 707985, 11 pages, 2011.
[8] Y. Adachi and N. Ohno, "Contribution of dectin-1 to the recognition of fungal cell wall products and the activation of innate immune response," Nihon Ishinkin Gakkai Zasshi, vol. 47, no. 3, pp. 185-194, 2006.

[9] S. Mehta, "The effects of nitric oxide in acute lung injury," Vascular Pharmacology, vol. 43, no. 6, pp. 390-403, 2005.

[10] S. Hong, J. E. Lee, C. Y. Kim, and G. J. Je, "Agmatine protects retinal ganglion cells from hypoxia-induced apoptosis in transformed rat retinal ganglion cell line," BMC Neuroscience, vol. 8, article 81, 2007.

[11] A. Halaris and J. Plietz, "Agmatine: metabolic pathway and spectrum of activity in brain," CNS Drugs, vol. 21, no. 11, pp. 885-900, 2007.

[12] J. Mu, K. Xie, L. Hou et al., "Subanesthetic dose of isoflurane protects against zymosan-induced generalized inflammation and its associated acute lung injury in mice," Shock, vol. 34, no. 2, pp. 183-189, 2010.

[13] J. Chen, Y. Li, L. Wang et al., “Therapeutic benefit of intravenous administration of bone marrow stromal cells after cerebral ischemia in rats," Stroke, vol. 32, no. 4, pp. 1005-1011, 2001.

[14] J. B. Clark and W. J. Nicklas, "The metabolism of rat brain mitochondria. Preparation and characterization," The Journal of Biological Chemistry, vol. 245, no. 18, pp. 4724-4731, 1970.

[15] J. Li, W. Liu, S. Ding et al., "Hyperbaric oxygen preconditioning induces tolerance against brain ischemia-reperfusion injury by upregulation of antioxidant enzymes in rats," Brain Research, vol. 1210, pp. 223-229, 2008.

[16] J. W. Soper and P. L. Pedersen, "Isolation of an oligomycinsensitive ATPase complex from rat liver mitochondria," Methods in Enzymology, vol. 55, pp. 328-333, 1979.

[17] R. F. Oppeltz, M. Rani, Q. Zhang, and M. G. Schwacha, "Burninduced alterations in toll-like receptor-mediated responses by bronchoalveolar lavage cells," Cytokine, vol. 55, no. 3, pp. 396401, 2011.

[18] T. Stevens, K. Ekholm, M. Gränse et al., “AZD9668: pharmacological characterization of a novel oral inhibitor of neutrophil elastase," Journal of Pharmacology and Experimental Therapeutics, vol. 339, no. 1, pp. 313-320, 2011.

[19] D. El Kebira, P. Gjorstrup, and J. G. Filepa, "Resolvin E1 promotes phagocytosis-induced neutrophil apoptosis and accelerates resolution of pulmonary inflammation," Proceedings of the National Academy of Sciences of the United States of America, vol. 109, no. 37, pp. 14983-14988, 2012.

[20] S. Matsuo, W. Yang, M. Aziz, A. Jacob, and P. Wang, "Cyclic arginine-glycine-aspartate attenuates acute lung injury in mice after intestinal ischemia/reperfusion," Critical Care, vol. 17, no. 1, article R19, 2013.

[21] X. Huang and Y. Y. Zhao, "Transgenic expression of FoxM1 promotes endothelial repair following lung injury induced by polymicrobial sepsis in mice," PLoS ONE, vol. 7, no. 11, Article ID e50094, 2012.

[22] J. J. Hoth, J. D. Wells, E. M. Hiltbold, C. E. McCall, and B. K. Yoza, "Mechanism of neutrophil recruitment to the lung after pulmonary contusion," Shock, vol. 35, no. 6, pp. 604-609, 2011.

[23] V. Galani, E. Tatsaki, M. Bai et al., "The role of apoptosis in the pathophysiology of Acute Respiratory Distress Syndrome (ARDS): an up-to-date cell-specific review," Pathology: Research and Practice, vol. 206, no. 3, pp. 145-150, 2010.

[24] T. R. Martin, J. C. Mathison, P. S. Tobias et al., "Lipopolysaccharide binding protein enhances the responsiveness of alveolar macrophages to bacterial lipopolysaccharide. Implications for 
cytokine production in normal and injured lungs," The Journal of Clinical Investigation, vol. 90, no. 6, pp. 2209-2219, 1992.

[25] N. Mariappan, C. M. Elks, B. Fink, and J. Francis, “TNF-induced mitochondrial damage: a link between mitochondrial complex I activity and left ventricular dysfunction," Free Radical Biology and Medicine, vol. 46, no. 4, pp. 462-470, 2009.

[26] S. Y. Cheranov and J. H. Jaggar, "TNF- $\alpha$ dilates cerebral arteries via $\mathrm{NAD}(\mathrm{P}) \mathrm{H}$ oxidase-dependent $\mathrm{Ca} 2+$ spark activation," The American Journal of Physiology-Cell Physiology, vol. 290, no. 4, pp. C964-C971, 2006.

[27] E. K. Wolthuis, A. P. J. Vlaar, G. Choi et al., "Recombinant human soluble tumor necrosis factor-alpha receptor fusion protein partly attenuates ventilator-induced lung injury," Shock, vol. 31, no. 3, pp. 262-266, 2009.

[28] M. A. Olman, K. E. White, L. B. Ware, M. T. Cross, S. Zhu, and M. A. Matthay, "Microarray analysis indicates that pulmonary edema fluid from patients with acute lung injury mediates inflammation, mitogen gene expression, and fibroblast proliferation through bioactive interleukin-1," Chest, vol. 121, supplement, no. 3, pp. 69S-70S, 2002.

[29] L. J. M. Cross and M. A. Matthay, "Biomarkers in acute lung injury: insights into the pathogenesis of acute lung injury," Critical Care Clinics, vol. 27, no. 2, pp. 355-377, 2011.

[30] R. Di Paola, E. Mazzon, C. Muià et al., "Protective effect of Hypericum perforatum in zymosan-induced multiple organ dysfunction syndrome: relationship to its inhibitory effect on nitric oxide production and its peroxynitrite scavenging activity," Nitric Oxide-Biology and Chemistry, vol. 16, no. 1, pp. 118-130, 2007.

[31] F. C. R. Souza, N. B. Gobbato, R. G. Maciel et al., "Effects of corticosteroid, montelukast and iNOS inhibition on distal lung with chronic inflammation," Respiratory Physiology and Neurobiology, vol. 185, no. 2, pp. 435-445, 2013.

[32] S. Cuzzocrea, E. Mazzon, L. Dugo et al., "Inducible nitric oxide synthase knockout mice exhibit resistance to the multiple organ failure induced by zymosan," Shock, vol. 16, no. 1, pp. 51-58, 2001.

[33] Q. Xie, Y. Kashiwabara, and C. Nathan, "Role of transcription factor NF- $\kappa \mathrm{B} /$ Rel in induction of nitric oxide synthase," The Journal of Biological Chemistry, vol. 269, no. 7, pp. 4705-4708, 1994.

[34] Z. You, D. Feng, H. Xu et al., "Nuclear factor- $\kappa$ B mediates onelung ventilation-induced acute lung injury in rabbits," Journal of Investigative Surgery, vol. 25, no. 2, pp. 78-85, 2012.

[35] P. J. Yu, J. R. Li, Z. G. Zhu et al., "Praeruptorin D and e attenuate lipopolysaccharide/hydrochloric acid induced acute lung injury in mice," European Journal of Pharmacology, vol. 710, no. 1-3, pp. 39-48, 2013.

[36] A. B. Nathens, R. Bitar, C. Davreux et al., "Pyrrolidine dithiocarbamate attenuates endotoxin-induced acute lung injury," American Journal of Respiratory Cell and Molecular Biology, vol. 17, no. 5, pp. 608-616, 1997.

[37] A. B. Lentsch, B. J. Czermak, N. M. Bless, N. van Rooijen, and P. A. Ward, "Essential role of alveolar macrophages in intrapulmonary activation of NF- $\kappa \mathrm{B}$," The American Journal of Respiratory Cell and Molecular Biology, vol. 20, no. 4, pp. 692-698, 1999.

[38] S. M. Sameer, S. S. Chakraborty, and R. R. Ugale, "Agmatine attenuates acquisition but not the expression of ethanol conditioned place preference in mice: a role for imidazoline receptors," Behavioural Pharmacology, vol. 24, no. 2, pp. 87-94, 2013.

[39] S. Bhalla, I. Ali, H. Lee, S. V. Andurkar, and A. Gulati, "Potentiation of oxycodone antinociception in mice by agmatine and BMS182874 via an imidazoline 12 receptor-mediated mechanism," Pharmacology Biochemistry and Behavior, vol. 103, no. 3, pp. 550-560, 2013.

[40] G. Olmos, N. deGregorio-Rocasolano, M. P. Regalado et al., "Protection by-imidazol(ine) drugs and agmatine of glutamateinduced neurotoxicity in cultured cerebellar granule cells through blockade of NMDA receptor," British Journal of Pharmacology, vol. 127, no. 6, pp. 1317-1326, 1999. 


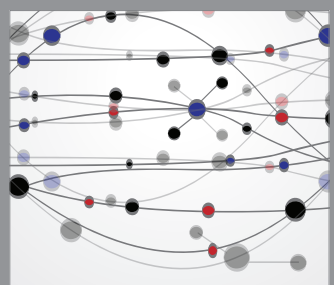

The Scientific World Journal
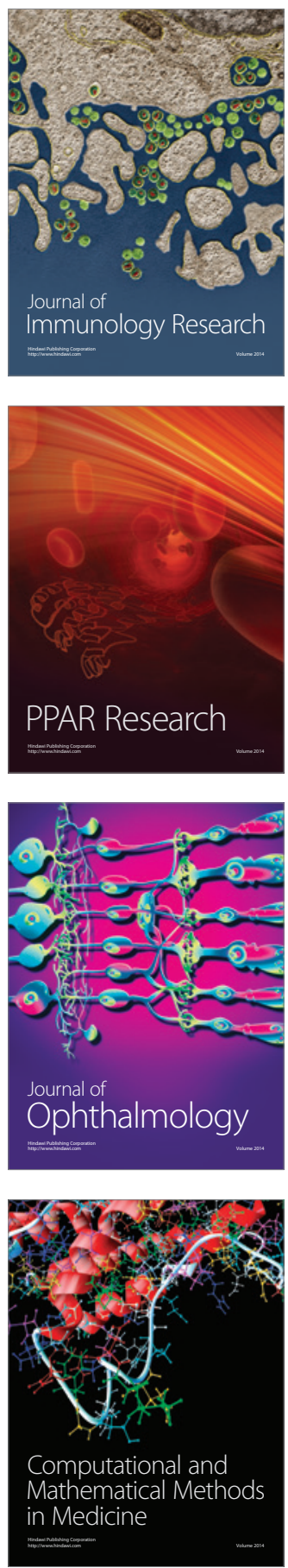

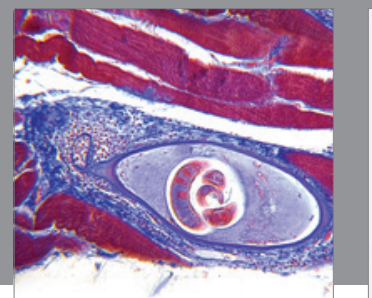

Gastroenterology

Research and Practice
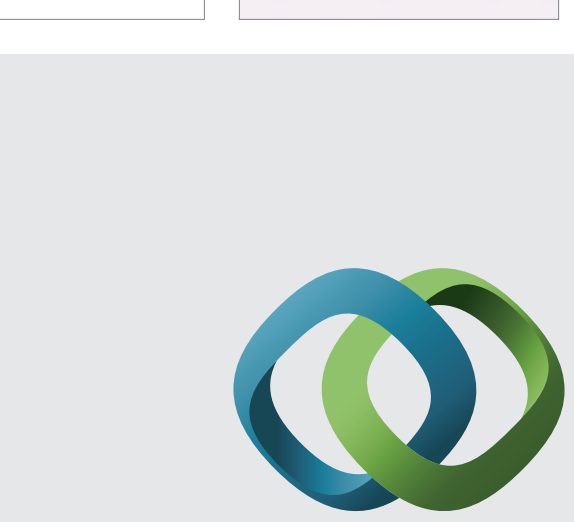

\section{Hindawi}

Submit your manuscripts at

http://www.hindawi.com
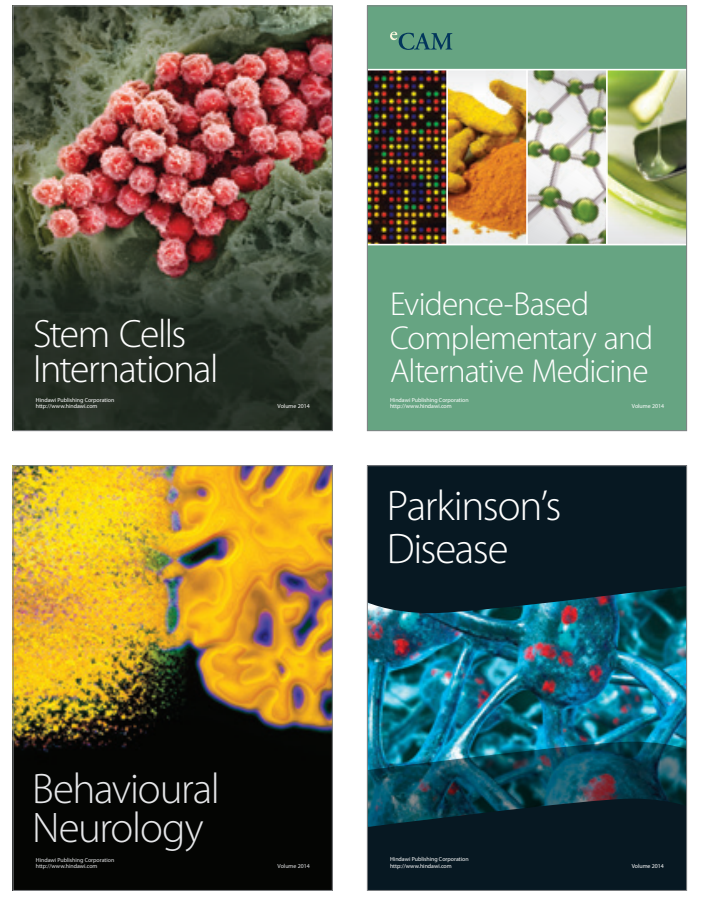
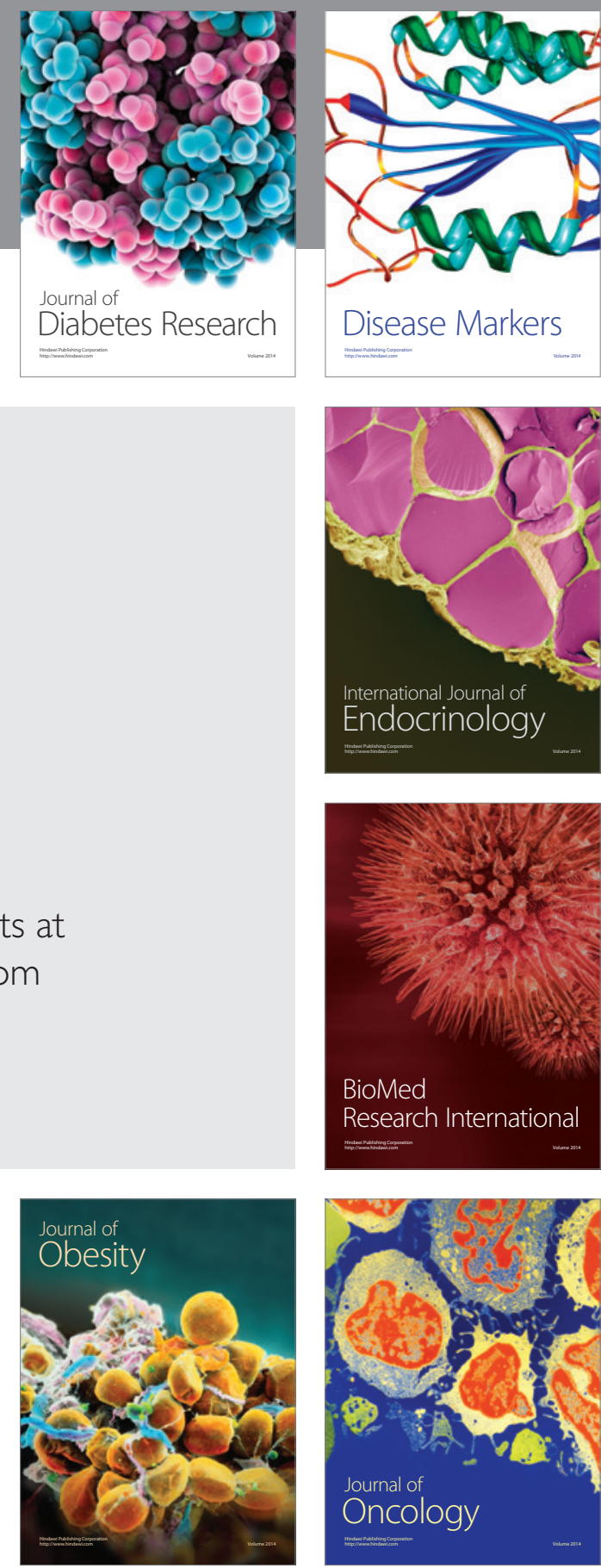

Disease Markers
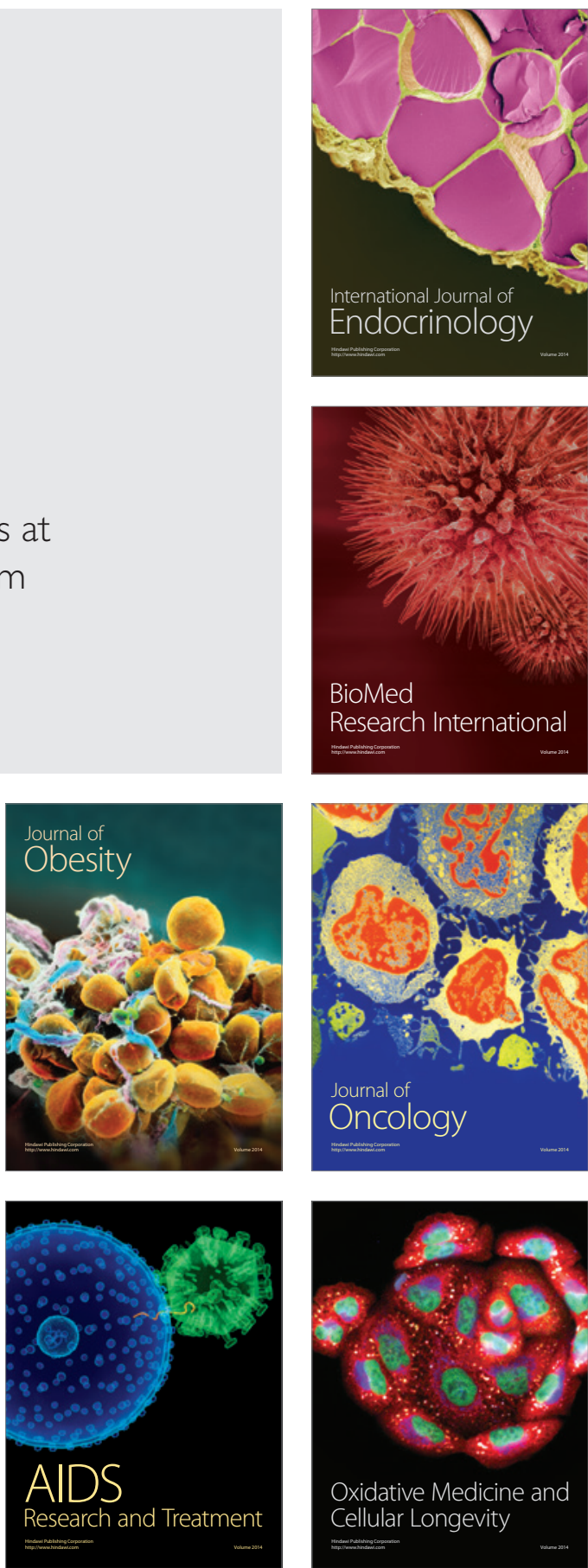